\title{
Multi-sensor biologgers and innovative training allow data collection with high conservation and welfare value in zoos
}

Holly M English ( $\square$ holly.english@ucdconnect.ie )

University College Dublin https://orcid.org/0000-0002-8854-6707

Luke Harvey

Zoological Society of London

Rory P Wilson

Swansea University https://orcid.org/0000-0003-3177-0107

Richard M Gunner

Swansea University https://orcid.org/0000-0002-2054-9944

Mark D Holton

Swansea University

Rosie Woodroffe

Institute of Zoology, Zoological Society of London https://orcid.org/0000-0003-2104-3133

Luca Börger

Swansea University https://orcid.org/0000-0001-8763-5997

\section{Research Article}

Keywords: biologging, captivity, daily diary, behaviour, welfare, enrichment, space use

Posted Date: May 26th, 2021

DOl: https://doi.org/10.21203/rs.3.rs-562677/v1

License: (c) (i) This work is licensed under a Creative Commons Attribution 4.0 International License.

Read Full License 


\section{Abstract}

Zoos are valuable resources for research, providing scientists with access to rare and elusive species in an easy to observe environment. Animal-attached loggers (aka biologgers) offer profound insight into animal behaviour. Their use in zoos has high yet largely untapped potential to collect data relevant for wild animal research and conservation but also welfare and enrichment monitoring of the zoo animals themselves. However, affixing biologgers to study animals can be problematic in captive settings, limiting the accessibility of this technology for use on zoo species which ordinarily need to be sedated for the fitting of such devices, including large carnivores. Here we show that biologging collars and crate-training allow collection of novel datasets on captive animals with high welfare and conservation value, using endangered African wild dogs (Lycaon pictus) tagged with tri-axial accelerometer and tri-axial magnetometer loggers, as a case study. Two yearling female wild dogs were fitted with biologging collars while sedated in preparation for translocation from London to Whipsnade Zoo, with data collected for 10-26 hours until collar detachment. Two adult male wild dogs at London Zoo were trained to accept collars in a modified crate in exchange for a food reward, which allowed fitting and detaching the collars without sedation, with data collected for 28 days. First, we show how accelerometer and magnetometer data allow detection of fine-scale individual differences in the recovery from sedation as well as withinand between-individual variation in activity patterns in relation to the type of food received (tong vs. rabbit and pony carcass). Using the vectorial dynamic body acceleration metric (VeDBA), a proxy for movement-related energy expenditure, further shows that daily energy expenditure was higher on days with partial pony carcass feeds compared to rabbit feeds but varied considerably between days where flesh pieces were fed with tongs. Using the dead-reckoning method allowed reconstruction of fine-scale (1 $\mathrm{Hz}$ locations) movement paths within enclosures, indoors and outdoors, allowing visualisation and quantification of fine-scale movement and space use differences between individuals and over time, for example in response to different enrichment methods. Using multi-sensor biologgers, combined with training captive animals to accept collars without the use of anaesthetic, can enable flexible, experimental approaches to data collection with minimal impact on study animals, providing novel understanding of relevance for both zoo and wild animals.

\section{Introduction}

Biologging, i.e., data collection of multiple variables using animal-attached tags, has seen considerable technological advancement in recent years (Ropert-Coudert and Wilson, 2005; Wilmers et al., 2015; Williams et al., 2020). Modern biologgers, such as Daily Diaries (hereafter DD; Wildbytes Ltd., Swansea University, UK), can collect fine-scale data at sub-second intervals, recording acceleration and compass data, as well as ambient temperature, pressure and light levels (Wilson et al., 2008; Williams et al. 2020). This level of detail allows detailed insight into animal activity and behaviour patterns, movements and space use, and individual state from the logger outputs (Wilson et al., 2018). Indeed, loggers such as the DD are typically used to investigate the behaviour of wild animals that cannot easily be observed (Brown et al., 2013) but also hold considerable potential in improving animal welfare in captive environments 
(Alex-Shorter et al. 2017). Understanding the behaviour of animals in human care can ensure effective welfare measures are in place under the $3 R$ s of reduction, refinement, and replacement framework (Russell et al., 1959; Flecknell, 2002). Logging data from captive animals can also aid behavioural interpretation of data from wild animals (English et al., in prep), allowing refinements to data collection and analysis methods before deployment on wild animals.

Zoos can benefit from logged data collected on their animals to examine their behaviour and improve enclosure design, enrichment activities, and feeding schedules to create more stimulating environments for zoo animals (Bassett and Buchanan-Smith, 2007; Mason et al., 2007). In particular, space use by captive animals is a potential indicator of enclosure appropriateness with implications for welfare (Hunter et al., 2014). Indeed, providing sufficient space for captive animals has knock-on effects for social interactions and stress experienced in shared enclosures (Greggor et al., 2018), as enclosures with more usable space facilitate exploratory movement and social companion choice (Browning and Maple, 2019). This also affects reproductive success, which is particularly important in the captive management of endangered species (Carlstead and Shepherdson, 1994; Morgan and Tromborg, 2007). Stereotypic behaviours and high infant mortality rates in captive carnivores are often more prevalent in wide-ranging species (Clubb and Mason, 2007). As accelerometers and magnetometers within biologgers record the necessary information to derive estimates for both heading (Han \& Wang, 2011; Gunner et al., in review) and speed (Bidder et al., 2012), the movement path of an animal fitted with these sensors can be reconstructed at a very fine scale, both indoors and outdoors, in a process known as dead-reckoning (Wilson and Wilson, 1988; Wilson et al., 1991; Bidder et al., 2015). This could provide specific, useful data with which to evaluate enclosure use and housing conditions of zoo animals, for example by detecting pacing, a common food anticipatory activity in captive carnivores (Bassett and Buchanan-Smith, 2007).

Although behavioural information can be collected unobtrusively in zoos with relative ease by simple observation, this approach is generally limited to zoo opening hours. This largely precludes the collection of nocturnal behaviour, as well as failing to collect data without the presence of a human observer. CCTV recordings can be used to fill in some of these knowledge gaps (Ferguson and Turner, 2013; Walsh, 2017), but also have limitations, including missing data when the study animals are out of shot and environmental factors affecting footage quality (Hall and Roshier, 2016).

Some of the advantages of biologgers in a zoo environment are, however, seemingly negated by problems, both ethical and technical (Hawkins, 2004; Minteer and Collins, 2013), of the animal capture and sedation process. On the other hand, biologging data, e.g., from accelerometers and magnetometers, has the potential to reveal and quantify even fine-scale individual differences in the recovery from sedation. However, capture and sedation is not always necessary because crate-training allows zookeepers to interact safely with zoo-housed animals without the use of sedation (Phillips et al., 1998; Rodden et al., 2012). Crate-training has successfully been used to collect blood samples from nyala (Tragelaphus angasii; Grandin et al., 1995), treat wounds and collect milk from bongo (Tragelaphus eurycerus; Phillips et al., 1998) and transport Marabou storks (Leptoptilos crumenifer, Miller and King, 2013). It is standard practice for large canids to be familiarised with crates prior to translocation (Rodden 
et al., 2012) and crate-training has been used to detect pregnancy in maned wolves (Chrysocyon brachyurus; Aitken-Palmer et al., 2017). As well as being key to captive animal transportation (Linhart, Adams \& Voracek, 2008) and veterinary interventions (Phillips et al., 1998), training exercises can also provide additional opportunities for behavioural stimulation and enrichment (Savastano et al., 2003; Szokalski et al., 2012; Westlund, 2014). Crate-training may therefore provide a safe method for deploying collars with loggers on carnivores while ensuring zoo-keeper safety, avoiding unnecessary sedation of animals, and providing a source of enrichment.

Here, we aim to showcase the opportunities and potential for zoos by combining innovative training and the use of multi-sensor biologgers for data collection with high conservation as well as animal welfare value. To do so we report data from fitting DD-equipped collars (cf. Wilson et al., 2008) to four captive African wild dogs (Lycaon pictus) in London and Whipsnade zoos. African wild dogs are the second-most endangered canid species occurring in Africa, with an estimated wild population of 6,600 individuals (Woodroffe and Sillero-Zubiri, 2012). Having experienced a range contraction of 93\% (Wolf and Ripple, 2017), captive studies have a potentially significant role to play in the conservation of this species. Furthermore, African wild dogs have an average pack territory size of $\sim 500 \mathrm{~km}^{2}$ (Gorman et al., 1998), potentially leaving them at a higher risk of developing stereotypic behaviours in captivity (Hunter et al., 2014). Previous attempts to assess the efficacy of wild dog enrichments have focused on zoo-keeper surveys rather than quantitatively assessing variation in activity between days with and without enrichment, and on days with different enrichment types (Cloutier and Packard, 2014). DDs can effectively quantify changes in activity levels and stereotypic behaviours (such as pacing) resulting from enrichment and allow assessing enclosure use. Fitting captive members of this species with loggers also facilitates the construction of accurate logger-based ethograms, so that future studies deploying this technology in the wild will have algorithms to allow behaviour to be accurately determined, even when observations are not possible, thus strongly benefitting conservation research.

Using the wild dog data from these two zoos, we (i) compare procedures for collar fitting with and without sedation, outlining for the latter a process for collaring captive African wild dogs through crate-training; (ii) assess post-sedation recovery, and enclosure use and activity patterns in relation to feeding regimes; and (iii) determine fine-scale movements and space use within enclosures through dead-reckoning.

\section{Materials And Methods}

\section{Ethics Statement}

Ethical approval was obtained for this study from Swansea University under the approval codes STU_BIOL_29066_280817112012_2 and SU-Ethics-Student-180917/2, and the AWERB approval code IP1617-8. The Zoological Society of London approved the work under the reference code ZDZ78.

\section{Collar Fitting Strategies: Sedation and Crate-training}


On the 27th of March 2017, two collars equipped with a Daily Dairy (DD; Wildbyte Technologies Ltd., UK) multi-sensor biologging tag (details below) and an automated drop-off mechanism, designed and constructed in Swansea University, were deployed on two female African wild dogs being moved from London to Whipsnade Zoo. These individuals were litter-mate yearlings, weighing 29 and $30 \mathrm{~kg}$ respectively. The collars were attached to the wild dogs whilst sedated by London Zoo veterinarians. These individuals were sedated so they could be placed in crates for transport via truck from London to Whipsnade Zoo and were not sedated explicitly to fit the collars.

Next, two adult males in London Zoo were trained to accept collars without being sedated over a period of 12 weeks from April to July 2017. Collars were designed in conjunction with ongoing behavioural training performed by London Zoo staff, and the final design was approved by zoo-keepers, a veterinarian, and an animal behaviour expert in London Zoo before deployment. These individuals were the oldest, from a pack of eight, and responded better to training than the other pack members, who were litter-mate yearlings. Both males weighed $>30 \mathrm{~kg}$. All pack members were born in captivity. A modified crate was made in London Zoo, featuring a weighing platform as its base and an end slat with a hole where the head could fit through to rest on a wooden platform, surrounded by a wire mesh (Fig. 1). First, the chosen individuals were familiarised with the crate, which was located in the indoor section of the enclosure. It was left in this position to allow free entry for wild dogs at any time they had indoor access. A food reward was given when a wild dog touched a metal rod used in contact training (Fig. 1). This reward was dispensed via metal tongs to ensure the zoo-keeper was not at risk of being bitten. A leather strap of the same material used to make the collars was hooked over the top of the hole and screwed into the sides of the platform. This allowed each wild dog plenty of space to fit their head through, while familiarising them with the feeling of the leather strap. Further training took place using rope to familiarise the wild dogs with neck contact, as this was a familiar and durable material. This was swapped for a noose when the wild dogs repeatedly took the rope into the enclosure. The noose facilitated approximate measurements of neck circumference per individual with a tape measure and collar deployment. CCTV cameras were set up in the London Zoo enclosure for the duration of the collar deployment (Fig. 2). Throughout the study period, the wild dogs were fed according to their normal feeding schedule, with daily feeds consisting of either a partial pony carcass (twice a week), whole rabbit carcasses (once a week) or $1 \mathrm{~kg}$ of meat pieces administered by tongs (four times a week).

\section{Collar Design}

For the Whipsnade Zoo deployment, standard leather dog collars were cut and sewn back together with nylon string. They featured a DD, with tri-axial accelerometers and magnetometers and environmental sensors (Wilson et al. 2008), and a drop-off mechanism governed by the DD turning on a separate battery connected to a burn resistor and double nylon line (60kg resistance), and a battery for each component. The DD was powered by two 2/3 A Lithium batteries and the burn resistor was powered by a $100 \mathrm{mAh} 3.7$ $V$ Lipo rechargeable battery. The DD was programmed to trigger the drop-off at a set time by passing high current through the resistor, which then becomes hot, causing the nylon line used to sew the collar to melt 
and sever, allowing the collar to drop. All components were contained in a robust 3D-printed nylon housing attached to a leather strap.

The London Zoo collars were made using leather belt blanks with a thickness of $4 \mathrm{~mm}$ and width of 28 $\mathrm{mm}$, and metal clasps with a breaking load of $200 \mathrm{~kg}$ (Fig. 1). A quick release clasp with a breaking load of $200 \mathrm{~kg}$ (Pets Bits Online, UK) was chosen so that collars could be snapped on, and later released, in one swift motion. The collars were not adjustable, due to concerns that a pack-mate might manipulate a looped collar, making it too tight on the neck. Conversely, if a collar was pulled loose, there was potential risk of a forelimb getting caught. The collars were initially riveted on one side only, so that adjustments could be made to get the best fit for both individuals. After zoo-keepers had adjusted the other side appropriately to fit the neck of the animals, collars were sent back to Swansea University to complete riveting and attach the logger housing. The housing was attached to sit at the ventral side of the neck so that the collar was bottom-weighted to reduce the incidence of collar roll, which affects accelerometer and magnetometer data. A supplementary training collar was provided while final adjustments were made. This allowed zoo-keepers to maintain regular training as the collars were completed. Training took place four days a week, from Tuesday to Friday inclusive, over a four-month training period. The training collar had a housing attached, containing two batteries and a DD, so that the weight would match that of the collars for deployment. The final weight of the collars, including all parts was $258 \mathrm{~g}$, approximately $0.86 \%$ of the wild dogs' body mass and thus well below the $3 \%$ rule in accordance with standard welfare guidelines (Kenward, 2000) and with collar size and weight conforming with recommendations for high quality biologging data (Dickinson et al., 2020).

Housing units were designed in Swansea University, with space for two A batteries and a DD. Data were stored on 2 GB microSD cards within the DDs. Two SAFT (Levallois-Perret, France) 2/3A Lithium batteries connected by diodes were used to power the DD. These housings and loggers were used for both the Whipsnade and London deployments. However, as the drop-off mechanism proved not robust enough to withstand wear by wild dogs (see Results), the collars for use in London Zoo did not feature a drop-off mechanism. The protective nylon housing for the DD and batteries was attached with countersunk screws and taped over with Tesa $\odot$ tape to ensure no irritation to the neck. The DD was set to record acceleration at $40 \mathrm{~Hz}$, magnetometry at $16 \mathrm{~Hz}$ and environmental data at $4 \mathrm{~Hz}$ for one individual in London Zoo; data from the other three wild dogs were recorded at $20 \mathrm{~Hz}, 8 \mathrm{~Hz}$ and $2 \mathrm{~Hz}$ by the respective sensors. This decision was taken following consideration of the advantages and disadvantages of sampling rate on data value and information content, in relation to power requirements and battery size (discussed by English et al., in prep).

\section{Data Interpretation}

Upon collar retrieval, DD data were inspected using the complementary data visualisation software Daily Diary Multiple Trace (DDMT; Wildbyte Technologies Ltd., UK). The data were calibrated to perform soft and hard iron corrections to the magnetometry channels (Bidder et al., 2015), accounting for any interference in magnetic data caused by metal on the collars themselves. 3D m-sphere visualisations (Williams et al., 2017) were used to inspect the data before and after corrections to confirm that 
magnetometry data had been corrected adequately to account for potential interference from metal enclosure fences.

Data were time-matched to concurrent behavioural observations for interpretation. Traces from the sedation recovery period for the two wild dogs moved to Whipsnade Zoo were visually inspected in DDMT. As well as graphing raw sensor data, DDMT computes a range of metrics calculated from acceleration and magnetometry data, including Vectorial Dynamic Body Acceleration (VeDBA; Wilson et al., 2008; Wilson et al., 2020). VeDBA is a reliable proxy for movement-related energy expenditure (Wilson et al., 2020) and speed (Bidder et al., 2012); it was used to examine activity patterns and space use via dead-reckoning (see below) over 12-hour active periods, from approximately $6 \mathrm{am}-6 \mathrm{pm}$, for the London Zoo data. This period was chosen to correspond with the daily active period of the wild dogs, as determined from visual inspection of biologging traces in DDMT and CCTV footage. For the Whipsnade Zoo data, tracks were reconstructed over approximate two-hour periods, for both wild dogs upon arrival in a small outdoor enclosure and indoor house, and for the initial exploration of the main outdoor enclosure for one individual the following day.

\section{Statistical Analyses}

The R Environment for Statistical Computing was used for statistical analyses (version 4.0.0; R Core Team, 2020). Logger data were first visualised and the relevant sections extracted using DDMT (Wildbyte Technologies Ltd, UK). All figures were plotted using ggplot2 (Wickham, 2016) and dead-reckoned tracks were mapped using ggmap (Kahle and Wickham, 2013). Segmented regression was used to determine the start and end points of rapid awakening from sedation using the segmented R package. Daily activity levels in response to food received were tested for significance through permutation testing for linear models with the ImPerm package (Wheeler \& Torchiano, 2016).

VeDBA, derived from the acceleration data, and heading values, derived from the acceleration and magnetometry data, were used to reconstruct fine-scale animal movement paths, in a process termed dead-reckoning (Wilson and Wilson, 1988; Bidder et al., 2015). Accumulation of errors along successive dead-reckoned location estimates can cause dead-reckoned paths to drift from true positions unless corrected using ground-truthed location data collected at a coarser temporal scale (Bidder et al. 2015). For this, location data were obtained by searching through CCTV footage and finding the longitude and latitude coordinates of known enclosure landmarks with Google Earth $\odot$. These verified locations were used to correct the dead-reckoned tracks. As dead-reckoning allows path reconstruction with location data supplied at flexible, irregular time intervals, the time periods between coordinates were not equal. VeDBA and heading data were smoothed to $1 \mathrm{~Hz}$ and then exported from DDMT to compute deadreckoned tracks in $\mathrm{R}$, including location-based error correction, following methods outlined in Gunner et al. (2021). Walking, trotting and running behaviours were identified in DDMT using a Boolean time series approach (English et al., in prep; cf. Wilson et al., 2018) and only data associated with these movement behaviours were exported for the calculation of dead-reckoned tracks. This allowed to avoid the path being affected by non-movement behaviours, as initial inspection indicated that frequent lifting and lowering of the head while resting could affect the path if not excluded. Instances of collar roll were rare 
but easily detected through visual inspection in DDMT due to changes in axes positions, and also removed from the subset of data exported to create dead-reckoned tracks. For Whipsnade Zoo, deadreckoned (DR) tracks were reconstructed following the arrival of the wild dogs in their new enclosure to capture initial exploratory behaviour. For the London Zoo wild dogs DR tracks were created over 12-hour time periods, from approximately $6 \mathrm{am}-6 \mathrm{pm}$. DR tracks were created to correspond with days where different food types were provided in London Zoo. As with the VeDBA data extraction, these times were chosen to correspond with the activity patterns of the wild dogs, and the sleeping den was the start and end location for all tracks (Fig. 2).

\section{Results}

\section{Collar Deployment via Sedation versus Crate-training}

The resistor-powered drop-off mechanism was not robust enough to withstand the high activity levels and social manipulation of collars exhibited by African wild dogs, with the first collar having dropped off after 10 hours $(1,749,880$ acceleration events collected at $20 \mathrm{~Hz})$ and the second after 26 hours $(2,307,400$ events at $20 \mathrm{~Hz})$ - significantly shorter than the planned three weeks of data collection. The non-drop-off collars with a quick-release clasp deployed in London Zoo collected data for the full planned four-week collar deployment period and were both deployed and retrieved without complications. These collars were deployed on the 13th of July 2017 and recorded until the 9th of August, providing approximately 1,344 hours of data, $672 \mathrm{~h}$ per individual $(93,246,120$ acceleration events at $40 \mathrm{~Hz}$ and $46,908,828$ at $20 \mathrm{~Hz}$ respectively). Collared wild dogs were monitored to ensure the collars did not attract negative attention from conspecifics. Particular care was taken to observe and film the wild dogs following initial collar fitting, but no collar-directed aggression was observed, apart from initial inspections by pack members upon arrival in Whipsnade Zoo.

Awakening after sedation showed similar VeDBA traces for both sedated wild dogs. The acceleration and VeDBA traces for the first minute after waking up for each individual show distinctive waveforms, shallow and repetitive, suggesting that both individuals were raising and lowering their heads repeatedly upon awakening, though without otherwise changing posture. The magnetometer traces highlight individual differences in the recovery between the two individuals, with one showing non-overlapping traces (Fig. 3a) while the second shows a periodic, repeated crossing of magnetometer channels (Fig. 3b), with the latter indicating changes in head orientation. Plots of VeDBA over a ten-minute interval from the moment each sedated individual had been placed in the transport crate and left to recover (Fig. 4) show that both individuals 'woke' from sedation approximately five minutes after being placed in their crates. The rapid wake-up phases lasted 28.8 seconds for one individual and 50.5 seconds for the other. VeDBA traces stabilised 3 and 3.4 minutes after wake-up respectively for the two wild dogs (Fig. 4).

\section{Activity Patterns in Relation to Feeding Regimes}

The study period for the two London Zoo wild dogs consisted of 14 days during which wild dogs received meat pieces via tongs, 8 days where a partial pony carcass was shared amongst the pack, and 4 days 
where each wild dog received a rabbit carcass. There were significant differences in daily activity levels, measured by total daily VeDBA, both between individuals $(p=0.006)$ and between days where different foods were provided $(p=0.036)$. Tong feeds of meat pieces showed the most variation in total daily VeDBA values, with both the lowest and highest activity days corresponding with tong feeding for both individuals (Table 1). Carcass feeds were associated with higher daily total VeDBA values than rabbit feeds (Fig. 5, Table 1).

\section{Enclosure Use via Dead-Reckoning}

Paths were successfully reconstructed encompassing both indoor and outdoor areas of the enclosures and showed no indication of pacing behaviour in any of the study individuals (Fig. 6). A dead-reckoned track representing the first exploration of the main outdoor enclosure area in Whipsnade the morning following translocation shows wide coverage of the new enclosure, traveling a cumulative distance of $1238 \mathrm{~m}$ (Fig. 7). The dead-reckoning procedure was considered highly accurate as paths approach but stay within the confines of the enclosure boundaries.

The dead-reckoned tracks shown in Fig. 8 were created using 24 longitude and latitude coordinates for location correction which had been extracted from CCTV camera footage. While the overall shape of these paths can be generated with fewer correction locations, this affects the cumulative distance estimates (Fig. 9). Visual inspections of carcass feeds showed clustering at the carcass position, but rabbit and flesh chunk feeds did not have discernible effects on daily enclosure use (Fig. 8). The cumulative distance moved of both individuals was highest for the rabbit feed days, at $466.08 \mathrm{~m}$ and $507.37 \mathrm{~m}$ respectively, compared to $332.34 \mathrm{~m}$ and $296.85 \mathrm{~m}$ for carcass feeds and $309.95 \mathrm{~m}$ and 249.68 $\mathrm{m}$ for tong feeds (Fig. 9). The London Zoo dead-reckoned tracks show markedly more restricted movements than the initial enclosure exploration seen in Whipsnade Zoo, as not all areas of the enclosure were visited daily.

\section{Discussion}

We show the potential of biologging in zoo-based research, with positive implications for animal welfare, using biologging data collected on four wild dogs from two zoos. The resulting data can be used to quantify responses to sedation, activity levels and enclosure use, with potential benefits to captive welfare management decisions and trialling methods to inform studies on wild counterparts.

Though the available timeframe for sedation recovery analysis was short, before translocation affected the logger data through crate lifting and transport via truck, the data presented here indicate quick recovery times. However, where longer-term consideration is required and possible, VeDBA may be examined over several days post-sedation to assess impacts on activity (Wilson et al., 2019). Nonetheless, here, despite the short timeframe available, VeDBA was useful in examining immediate responses and activity following sedation recovery (Figs. 3-4). The success of the crate-training and the second collar design that followed suggest that future translocations may implement similar training procedures and thus negate the need for sedation prior to transport. Conversely, future cases where 
sedation is still required for veterinary procedures without translocations would allow individual differences in sedation recovery to be examined over longer timeframes. Sedating animals comes with many risks, such as hypothermia, respiratory depression, and even mortality in rare cases (Stegmann, 2000; Muir and Hubbell, 2014). Avoiding anaesthetic in the second deployment allowed collection of valuable data without these risks with the added advantage that training exercises in captive animals provide a source of enrichment (Melfi, 2013).

Increased activity levels are often associated with improved captive welfare, but not if the activity stems from stereotypic behaviours (Bashaw et al., 2003; Andrews and Ha, 2014); using dead-reckoned tracks we could investigate this in unprecedented detail (see below). Both individuals collared in London Zoo showed higher daily VeDBA values when a partial pony carcass had been fed compared to rabbits but days where flesh chunks had been fed showed greatest variability in VeDBA (Fig. 5). This could be an artefact of sample size, as flesh chunk feed days were the most prevalent, occurring four times a week compared to twice a week (partial pony carcass) and once a week (rabbits). Variety in feeding times and spatial distribution of food items are widely reported to be effective enrichment techniques for captive carnivores (Shepherdson et al., 1993; Cummings et al., 2007; Kistler et al., 2009; Wagman et al., 2018). Feeding in London Zoo occurred at approximately the same time each day during the study period, but the different foods provided were given from different enclosure locations and required different handling behaviours from the wild dogs. Hence, food type variation may play a role in the absence of stereotypies detected from the logger data or CCTV footage. Food items which stimulate natural foraging and food handling behaviours, such as the partial pony carcasses and whole rabbits provided here, can positively stimulate captive carnivore behaviour for several days after being given and may account for the high variability in activity levels on days when flesh chunks were fed (Shepherdson et al., 1993; Wagman et al., 2018).

In Whipsnade Zoo, we quantified the exploratory behaviour of African wild dogs released into a new enclosure for the first time. Translocating animals between zoos is crucial for maintaining genetic integrity of species in captive breeding programmes (Lacy, 2013). Despite the importance and prevalence of this activity, there is relatively little consideration of the effects of between-zoo translocation in the literature. The preliminary data here depicting space use immediately following a translocation event highlight the use of logging devices as a promising method for understanding post- translocation behaviour of endangered captive species. Future work should consider prolonged logger deployment, with data collection also collected in the zoo occupied before translocation for comparative purposes where feasible.

'Pacing' is a locomotory stereotypy which typically involves pacing over and back along a fixed route, typically a straight line but sometimes in circles or figures of eight shapes (Clubb and Vickery, 2006). This distinctive movement behaviour should form clear patterns in dead-reckoned tracks where it occurs, but no evidence of stereotypic pacing was detected in the African wild dogs in this study. Stereotypies are thought to arise when captive animals cannot conduct their natural behaviours, in particular those related to ranging and foraging strategies (Clubb and Mason, 2003). While conditions in captivity can never 
match the large territory sizes of free-roaming African wild dogs, feeding enrichment is feasible and widely implemented (Packard et al., 2010; Price, 2010; Cloutier and Packard, 2014). Food-related enrichment is thought to be the most effective in reducing or eliminating African wild dog stereotypies (Cloutier and Packard, 2014) but positive benefits have been found from adding even short training periods to the care schedules of pacing captive wild dogs (Shyne and Block, 2010). The rotation of food type given and incorporation of whole rabbits and partial pony carcass feeds likely contributes to the absence of stereotypic pacing. The regular training exercises for collar fitting may also be considered as enrichment (Westlund, 2014; Fernandez et al, 2019).

The low cumulative distance estimates for the London Zoo dead-reckoned tracks are in accordance with the old age of both adult males and though cumulative distance estimates vary with the frequency of location corrections, this study highlights the value of this metric as a relative measure to compare between days. This has wider implications for other studies implementing dead-reckoning methods and may provide guidance for selecting sampling frequency in wild deployments where loggers are being used in conjunction with units collecting location data such as through GPS or Argos satellite telemetry. Performing behaviour classification to isolate movement from non-movement behaviours prior to reconstructing dead-reckoned paths was an important methodological step to ensure tracks stayed within enclosure boundaries. This too has wider implications, suggesting that at least preliminary behaviour classification is an important and under-utilised step of the dead-reckoning procedure. This study provides important evidence in response to pertinent questions regarding sampling frequencies and behaviour classification in track reconstruction procedures and warrants further study, particularly involving animals in enclosures.

Developing new training regimes such as the one outlined here facilitates the collection of useful activity data which can inform animal welfare in captive settings, which is broadly applicable to a range of species living in zoos. These training activities also have positive consequences for captive animal health. Continued training with the modified crate has facilitated regular collection of individual body mass data. A number of veterinary interventions have also been streamlined by continued crate training while avoiding anaesthesia, including administering eye drops to an individual that developed an ulcer and taking samples of facial lesions which broke out in multiple pack members with unknown cause (L. Harvey, pers. obs.). Where sedation is still required, crate training has also been used in London Zoo to calmly separate two wild dogs for procedures requiring general anaesthesia. Crate training is felt by staff to have increased the general training standard by increasing the trust between keeper and animal, with one individual having successfully undergone venepuncture without sedatives in another training area. As such, of the two different collaring approaches used, the quick-release collars and associated training procedures were more advantageous for the zoo environment than the drop-off collars.

There is a lack of consensus regarding whether tags on collars, or even collars themselves, have negative impacts on animal behavioural patterns and a resultant need for species-specific assessments (Horback et al., 2012). Wide-ranging carnivores are particularly vulnerable to stereotypic behaviours (Clubb and Mason, 2003), and so training captive carnivores to accept collars for the collection of logging data could 
be beneficial to their welfare by offering detailed insight into behavioural patterns. However, social carnivores should be monitored to assess reactions from conspecifics to collars.

\section{Conclusion}

Biologging studies conducted in captivity provide information on the space use and activity patterns of captive animals. As well as the implications for captive carnivore welfare, this study highlights the enormous research potential of zoos to contribute to biologging studies by providing opportunities to develop new collar designs and trial data interpretation methods in a setting where non-domesticated animals can be observed with ease. The training exercise outlined here showcases a creative mechanism for fitting collars on a captive carnivore, with benefits for captive animal welfare and veterinary care.

\section{Declarations}

\section{Acknowledgements}

We would like to acknowledge all ZSL staff and management for facilitating this research, particularly Teague Stubbington, Gemma Metcalf, Malcolm Fitzpatrick, and Jim Mackie. Sincere thanks to Phil Hopkins and Julian Kivell who assisted in collar design at Swansea University. Thanks also to Simone Ciuti for advice and numerous discussions about the manuscript. HME is funded by an Irish Research Council Government of Ireland postgraduate scholarship.

\section{Conflict of interest}

The authors confirm that there are no conflicts of interest to declare.

\section{References}

Aitken-Palmer C., A.C.Z.M. D., Ware L. H., Braun L., LANG K., JOYNER, P. H. (2017) Novel radiographic technique for pregnancy detection in the maned wolf (Chrysocyon brachyurus) without anesthesia. Journal of Zoo and Wildlife Medicine, 48, 204-207.

Alex Shorter K., Shao Y., Ojeda L., Barton K., Rocho-Levine J., van der Hoop J., Moore M. (2017) A day in the life of a dolphin: Using bio-logging tags for improved animal health and well-being. Marine Mammal Science, 33: 785-802.

Andrews N.L., Ha J.C. (2014) The effects of automated scatter feeders on captive grizzly bear activity budgets. Journal of Applied Animal Welfare Science, 17, 148-156.

Bashaw M.J., Bloomsmith M.A., Marr M.J., Maple T.L. (2003) To hunt or not to hunt? A feeding enrichment experiment with captive large felids. Zoo Biology, 22, 189-198. 
Bassett L., Buchanan-Smith H.M. (2007.) Effects of predictability on the welfare of captive animals. Applied Animal Behaviour Science, 102, 223-245.

Bidder O.R., Soresine M., Shepard E.L., Halsey L.G., Quintana F., Gómez-Laich A., Wilson R.P. (2012) The need for speed: testing acceleration for estimating animal travel rates in terrestrial dead-reckoning systems. Zoology, 115, 58-64.

Bidder O.R., Walker J. S., Jones M.W., Holton M.D., Urge P., Scantlebury D.M., Marks N. J., Magowan E.A., Maguire I.E., Wilson R.P. (2015) Step by step: reconstruction of terrestrial animal movement paths by dead-reckoning. Movement Ecology, 3, 1-16.

Brown D.D., Kays R., Wikelski M., Wilsom R.P., Klimley A.P. (2013) Observing the unwatchable through acceleration logging of animal behavior. Animal Biotelemetry, 1, 20.

Browning H., Maple T.L. (2019) Developing a Metric of Usable Space for Zoo Exhibits. Frontiers in Psychology, 10, 791.

Carlstead K., Shepherdson D. (1994) Effects of environmental enrichment on reproduction. Zoo Biology, $13,447-458$.

Cloutier T.L., Packard J.M. (2014) Enrichment options for African painted dogs (Lycaon pictus). Zoo Biology, 33, 475-480.

Clubb R., Mason G. (2003) Animal welfare: captivity effects on wide-ranging carnivores. Nature, 425, 473474.

Clubb R., Mason G.J. (2007) Natural behavioural biology as a risk factor in carnivore welfare: How analysing species differences could help zoos improve enclosures. Applied Animal Behaviour Science, $102,303-328$.

Clubb R., Vickery S. (2006) Locomotory stereotypies in carnivores: does pacing stem from hunting, ranging, or frustrated escape. In: Mason G., Rushen J. (eds) Stereotypic Animal Behaviour: Fundamentals and Applications to Welfare, Trowbridge, UK: Cromwell Press.

Cummings D., Brown J.L., Rodden M.D., Songsasen N. (2007) Behavioral and physiologic responses to environmental enrichment in the maned wolf (Chrysocyon brachyurus). Zoo Biology, 26, 331-343.

Ferguson A., Turner B. (2013) Reproductive parameters and behaviour of captive short-beaked echidna (Tachyglossus aculeatus acanthion) at Perth Zoo. Australian Mammalogy, 35, 84-92.

Fernandez E.J., Kinley R.C., Timberlake W. (2019) Training penguins to interact with enrichment devices for lasting effects. Zoo Biology, 38, 481-489.

Flecknell P. (2002) Replacement, reduction and refinement. Altex, 19, 73-78. 
Gorman M.L., Mills M.G., Raath J.P., SPEAKMAN J.R. (1998) High hunting costs make African wild dogs vulnerable to kleptoparasitism by hyaenas. Nature, 391, 479-481.

Grandin T., Rooney M.B., Phillips M., Cambre R.C., Irlbeck N.A., GRAFFAM W. (1995) Conditioning of nyala (Tragelaphus angasi) to blood sampling in a crate with positive reinforcement. Zoo Biology, 14, 261-273.

Greggor A., Vicino G.A., Swaisgood R.R., Fidgett A.L., Brenner D., Kinney M.E., Farabaugh S.M., Masuda B., Lamberski N. (2018) Animal welfare in conservation breeding: applications and challenges. Frontiers in Veterinary Science, 5, 323.

Gunner R.M., Holton M.D., Scantlebury M.D., van Schalkwyk L., English H.M., Williams H.J., Hopkins P., Quintana F., Gómez-Laich A., Börger L., Redcliffe J., Yoda K., Yamamoto T., Ferreira S., Govender D., Viljoen P., Bruns A., Bell S.H., Marks N., Bennet N.C., Tonini M.H., Duarte C.M., van Rooyen M.C., Bertelsen M.F., Tambling C.J., Wilson R.P. (in review at Animal Biotelemetry) Dead-Reckoning Animal Movements in RA Reappraisal Using Gundog.Tracks. Preprint available via ResearchSquare. 10.21203/RS.3.RS311276/V1

Hall C., Roshier A. (2016) Getting the measure of behavior... is seeing believing? Interactions, 23, $42-46$.

Han S., Wang J. (2011) A novel method to integrate IMU and magnetometers in attitude and heading reference systems. Journal of Navigation, 64, 727-738.

Hawkins P. (2004) Bio-logging and animal welfare: practical refinements. Memoirs of the National Institute of Polar Research, 58-68.

Horback K.M., Miller L.J., Andrews J., Kuczaj II S.A., Anderson M. (2012) The effects of GPS collars on African elephant (Loxodonta africana) behavior at the San Diego Zoo Safari Park. Applied Animal Behaviour Science, 142, 76-81.

Hunter S.C., Gusset M., Miller L.J., Somers M.J. (2014) Space Use as an Indicator of Enclosure Appropriateness in African Wild Dogs (Lycaon pictus). Journal of Applied Animal Welfare Science, 17, 98110.

Kenward R.E. (2000) A manual for wildlife radio tagging, Academic Press.

Kistler C., Hegglin D., Würbel H., König B. (2009) Feeding enrichment in an opportunistic carnivore: The red fox. Applied Animal Behaviour Science, 116, 260-265.

Lacy R.C. (2013) Achieving true sustainability of zoo populations. Zoo Biology, 32, 19-26.

Linhart P., Adams D.B., Voracek T. (2008) The international transportation of zoo animals: conserving biological diversity and protecting animal welfare. Veteriniaria Italia, 44, 49-57. 
Mason G., Clubb R., Latham N., Vickery S. (2007) Why and how should we use environmental enrichment to tackle stereotypic behaviour? Applied Animal Behaviour Science, 102, 163-188.

Melfi V. (2013) Is training zoo animals enriching? Applied Animal Behaviour Science, 147, 299-305.

Miller R., King C.E. (2013) Husbandry training, using positive reinforcement techniques, for Marabou stork Leptoptilos crumeniferus at Edinburgh Zoo. International Zoo Yearbook, 47, 171-180.

Minteer B.A., Collins J.P. (2013) Ecological ethics in captivity: Balancing values and responsibilities in zoo and aquarium research under rapid global change. Ilar Journal, 54, 41-51.

Morgan K.N., Tromborg C.T. (2007) Sources of stress in captivity. Applied Animal Behaviour Science, 102, 262-302.

Muir W.W., Hubbell J.A. (2014) Handbook of Veterinary Anesthesia-E-Book, Elsevier Health Sciences.

Packard J.M., Turner S.J., Shepard S. (2010) Behavioral enrichment for African wild dogs (Lycaon pictus): response to stimuli used in an ongoing program at the Houston Zoo. Biodiversity Stewardship Report No. BS10-2 Biodiversity Stewardship Lab, TAMUS, College Station, Texas.

Phillips M., Grandin T., Graffam W., Irlbeck N.A., Cambre R.C. (1998) Crate conditioning of bongo (Tragelaphus eurycerus) for veterinary and husbandry procedures at the Denver Zoological Gardens. Zoo Biology, 17, 25-32.

Price L.J. (2010) A preliminary study of the effects of environmental enrichment on the behaviour of captive African wild dogs (Lycaon pictus). Bioscience Horizons, 3, 132-140.

Rodden M., Siminski P., Waddell W., Quick M. (2012) Large Canid (Canidae) Care Manual. Silver Spring, MD: Association of Zoos and Aquariums, Canid Taxon Advisory Group.

Ropert-Coudert Y., Wilson R.P. (2005) Trends and perspectives in animal-attached remote sensing. Frontiers in Ecology and the Environment, 3, 437-444.

R Core Team (2020) R: A language and environment for statistical computing. R Foundation for Statistical Computing, Vienna, Austria. URL https://www.R-project.org/.

Russell W.M.S., Burch R.L., HUME C.W. (1959) The principles of humane experimental technique.

Savastano G., Hanson A., McCann C. (2003) The Development of an Operant Conditioning Training Program for New World Primates at the Bronx Zoo. Journal of Applied Animal Welfare Science, 6, 247261.

Shepherdson D.J., Carlstead K., Mellen J.D., Seidensticker J. (1993) The influence of food presentation on the behavior of small cats in confined environments. Zoo Biology, 12, 203-216. 
Shyne A., Block M. (2010) The effects of husbandry training on stereotypic pacing in captive African wild dogs (Lycaon pictus). Journal of Applied Animal Welfare Science, 13, 56-65.

Stegmann G. (2000) Isoflurane anaesthesia in an African wild dog, Lycaon pictus. Journal of the South African Veterinary Association, 71, 246.

Szokalski M.S., Litchfield C.A., Foster W.K. (2012) Enrichment for captive tigers (Panthera tigris): Current knowledge and future directions. Applied Animal Behaviour Science, 139, 1-9.

Wagman J.D., Lukas K.E., Dennis P.M., Willis M.A., Carroscia J., Gindlesperger C., Schook M.W. (2018) A work-for-food enrichment program increases exploration and decreases stereotypies in four species of bears. Zoo Biology, 37, 3-15.

Walsh B. (2017) Asian elephant (Elephas maximus) sleep study - long-term quantitative research at Dublin Zoo. Journal of Zoo and Aquarium Research, 5, 82-85.

Westlund K. (2014) Training is enrichment-and beyond. Applied Animal Behaviour Science, 152, 1-6.

Wheeler B., Torchiano M. (2016) Package 'ImPerm'. R package vignette, 2(0).

Williams H.J., Taylor L.A., Benhamou S., Bijleveld A.I., Clay T.A., de Grissac S., Demšar U., English H.M., Franconi N., Gómez-Laich A., Griffiths R.C., Kay W.P., Morales J.M., Potts J.R., Rogerson K.F., Rutz C., Spelt A., Trevail A.M, Wilson R.P., Börger L. (2020) Optimising the use of bio-loggers for movement ecology research. Journal of Animal Ecology, 89, 186-206.

Wilmers C.C., Nickel B., Bryce C.M., Smith J.A., Wheat R.E., Yovovich V. (2015) The golden age of biologging: how animal-borne sensors are advancing the frontiers of ecology. Ecology, 96, 1741-1753.

Wilson R.P., Börger L., Holton M.D., Scantlebury D.M., Gómez-Laich A., Quintana F., Rosell F., Graf P.M., Williams H.J., Gunner R., Hopkins L., Marks N., Geraldi N.R., Duarte C.M., Scott R., Strano M.S., Robotka H., Eizaguirre C., Fahlman A., Shepard E.L.C. (2020) Estimates for energy expenditure in free-living animals using acceleration proxies: A reappraisal. Journal of Animal Ecology, 89, 161-172.

Wilson R.P., Wilson M.P. (1988) Dead reckoning: a new technique for determining penguin movements at sea. Meeresforschung, 32, 155-158.

Wilson R.P., Holton M.D., di Virgilio A., Williams H.J., Shepard E.L.C., Lambertucci S., Quintana F., Sala J. E., Balaji B., Lee E.S., Srivastava M., Scantlebury D.M., Duarte C.M. (2018) Give the machine a hand: A Boolean time-based decision-tree template for rapidly finding animal behaviours in multisensor data. Methods in Ecology and Evolution. 9: 2206- 2215.

Wilson R.P., Holton M.D., Wilson V.L., Gunner R.M., Tysse B., Wilson G.I., Quintana F., Duarte C.M., Scantlebury D.M. (2019) Towards informed metrics for examining the role of human-induced animal responses in tag studies on wild animals. Integrative Zoology, 14, 17-29. 
Wilson R.P., Shepard E.L.C., LIEBSCH N. (2008) Prying into the intimate details of animal lives: use of a daily diary on animals. Endangered Species Research, 4, 123-137.

Wilson R.P., Wilson M.P., Link R., Mempel H., Adams N.J. (1991) Determination of movements of African penguins Spheniscus demersus using a compass system: dead reckoning may be an alternative to telemetry. Journal of Experimental Biology, 157, 557-564.

Wolf C., Ripple W.J. (2017) Range contractions of the world's large carnivores. Royal Society Open Science, 4, 170052.

Woodroffe R., Sillero-Zubiri C. (2012) Lycaon pictus [Online]. The IUCN Red List of Threatened Species. [Accessed 07/04/2017].

\section{Table 1}

Table 1. Median, minimum, and maximum total daily VeDBA (calculated from the core 12hour diurnal active period) per individual per food received on a given day. Days where pony carcasses were provided had the highest median VeDBA values, while days with meat piece feeds had the minimum and maximum total daily VeDBA values during the study period, for both individuals.

\section{Individual}

Food Received

Total VeDBA $(g)$ over $12 \mathrm{hrs}$ Median

Minimum

Maximum

Kruger

Meat pieces

70155.85

43815.89

112067.2

Pony carcass

Rabbit carcass

Selous

Meat pieces

Pony carcass

Rabbit carcass
91633.92

67549.01

89453.04

113506.3

84155.65
77822.03

128353.0

68964.06

59341.38

48758.45

108722.1

104619.6

\section{5}

78127.14

89588.09

\section{Figures}



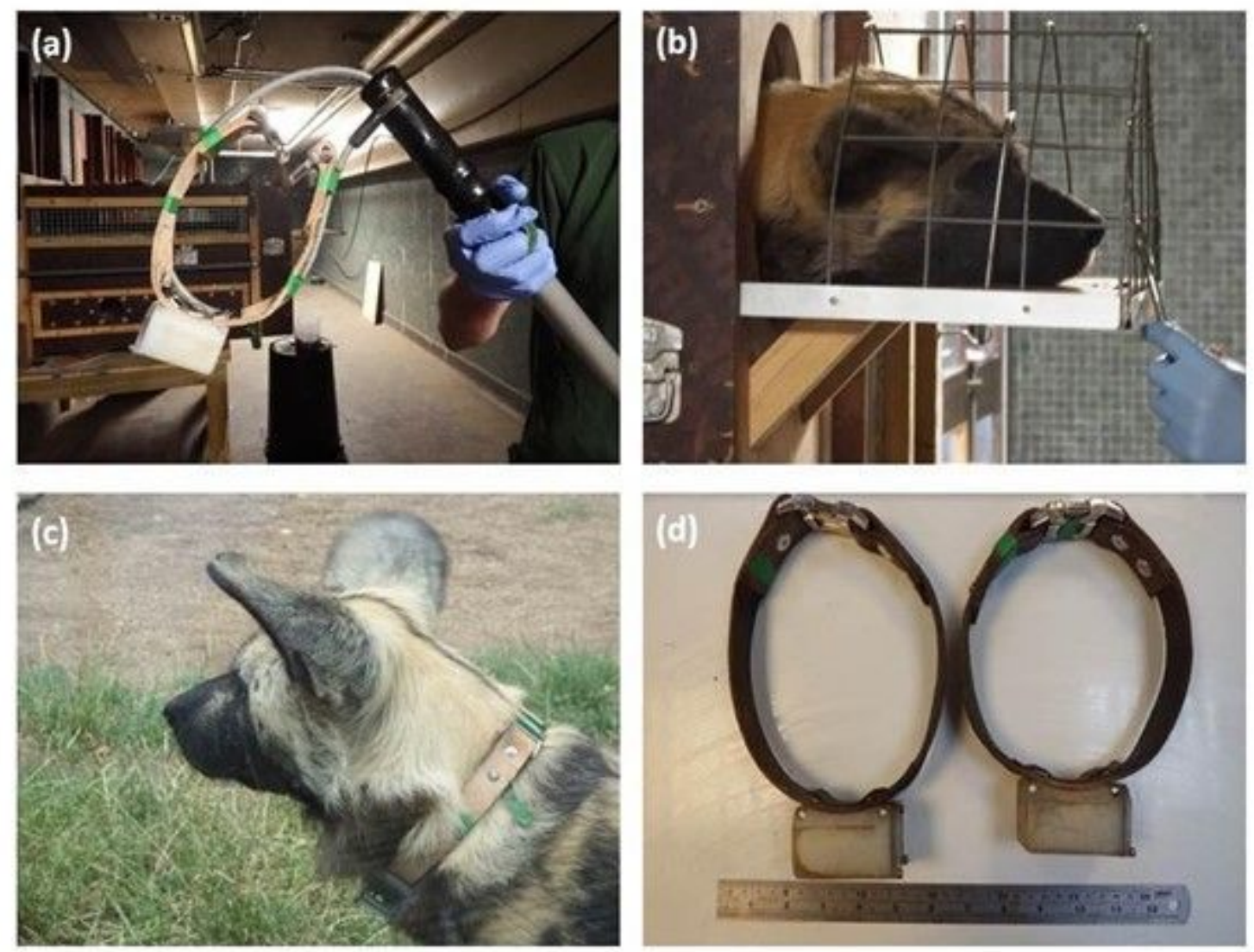

\section{Figure 1}

(a) The collar was attached to a noose with weak tape prior to deployment. (b) African wild dog in an early training session. (c) An African wild dog wearing the deployed collar. (d) Collars after retrieval.

\section{Main Paddock Small Paddock}

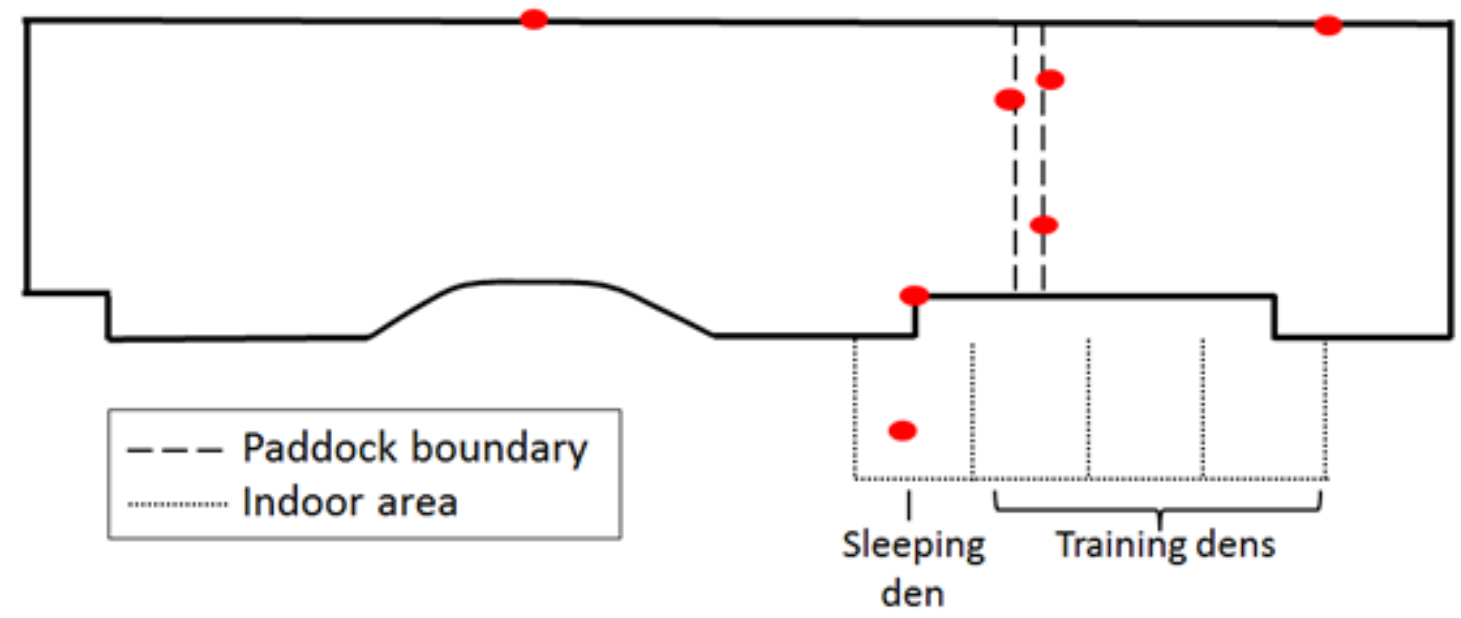

Figure 2

A schematic of the London Zoo African wild dog enclosure indicating the position of CCTV cameras in red. These cameras were used to extract longitude and latitude coordinates to correct the dead-reckoned tracks. 

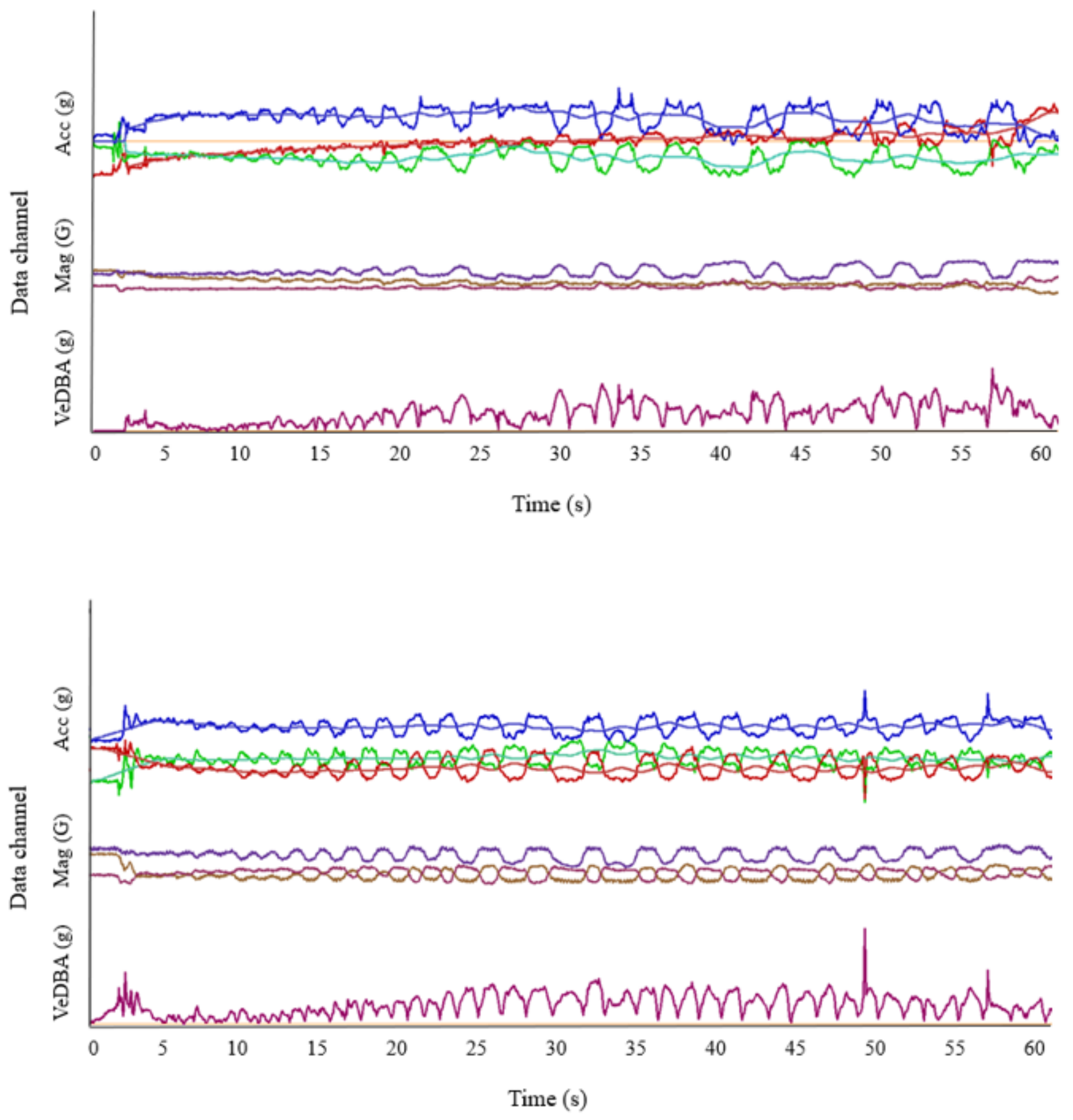

Figure 3

Acceleration, magnetometry and VeDBA traces from the first minute after waking up from sedation for the two wild dogs moved to Whipsnade Zoo (a) Brandy, (b) BeeBee, respectively. Tri-axial acceleration data were recorded at $20 \mathrm{~Hz}$ (blue = heave, red = surge, green = sway). Raw acceleration depicts movement, while the smoothed line running through each acceleration axis indicates a lack of postural change. Acceleration data were smoothed at the default rate of 80 events in DDMT. 

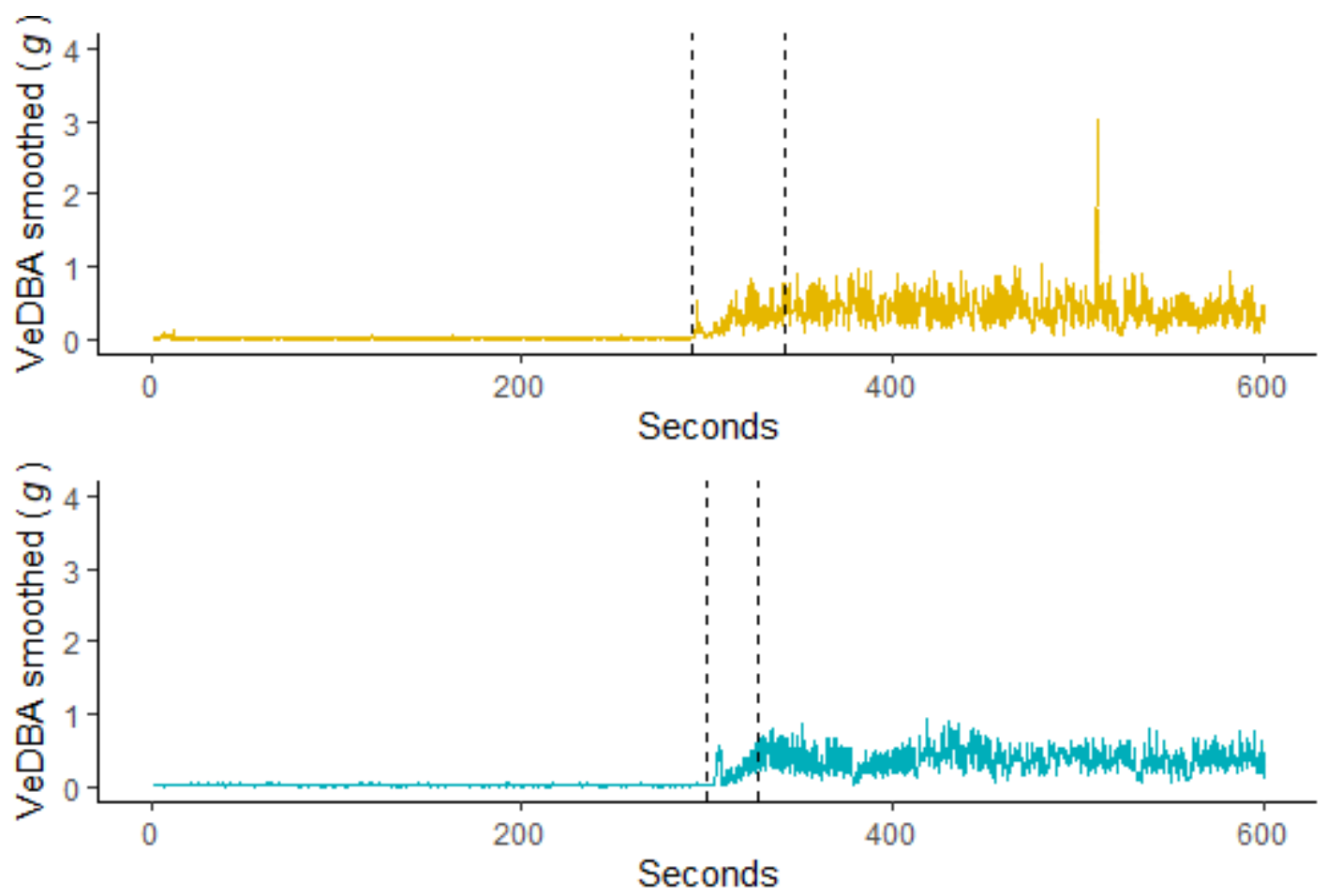

Figure 4

VeDBA over time for ten minutes following two African wild dogs, (a) Brandy and (b) BeeBee, being placed into the transport crate following a veterinary check and collar fitting. Both individuals became fully alert after approximately 5 minutes.

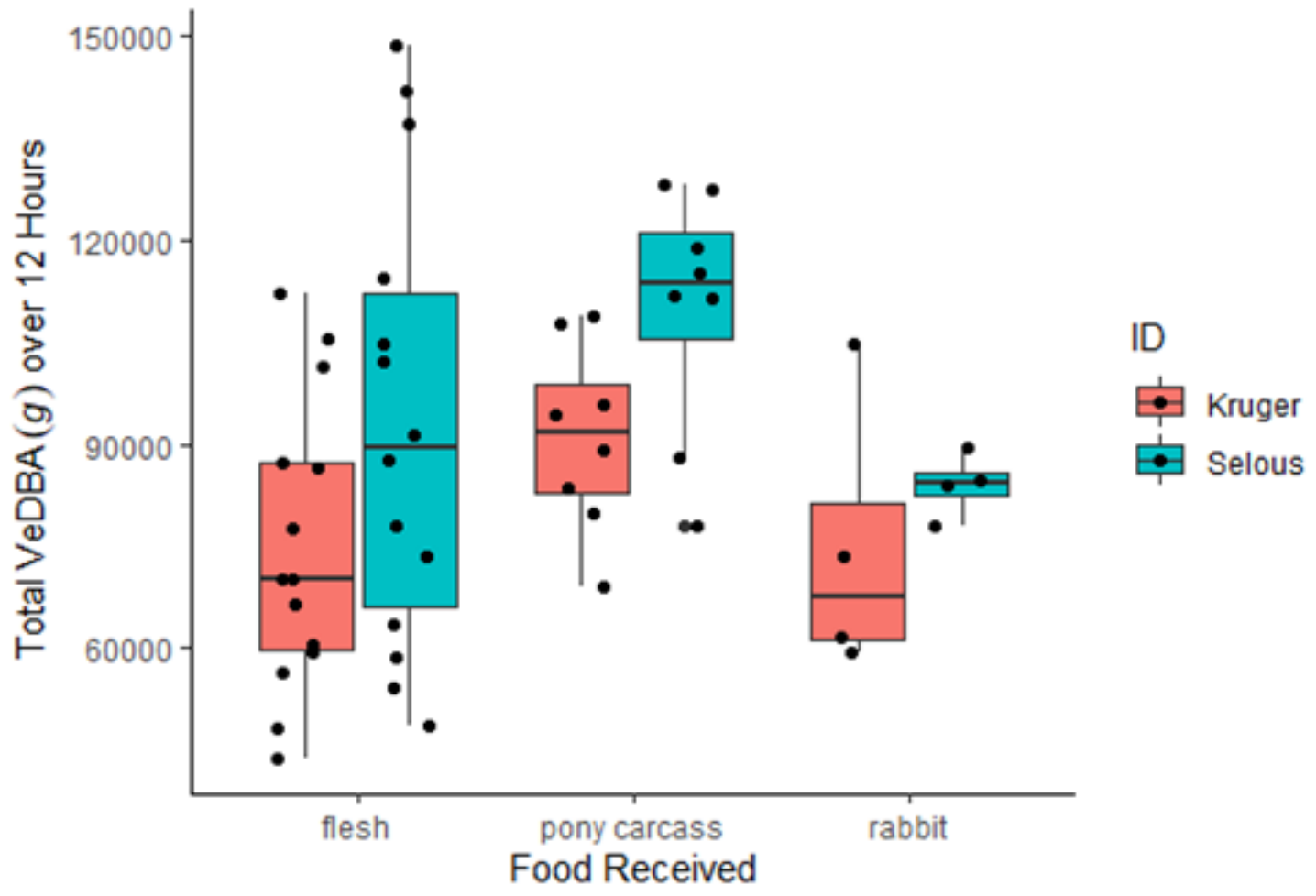

Figure 5 
Total VeDBA values over a 12-hour period for two individuals in relation to food type received on a given day at $40 \mathrm{~Hz}$ (Kruger, salmon shading) and $20 \mathrm{~Hz}$ (Selous, blue shading).

(a)

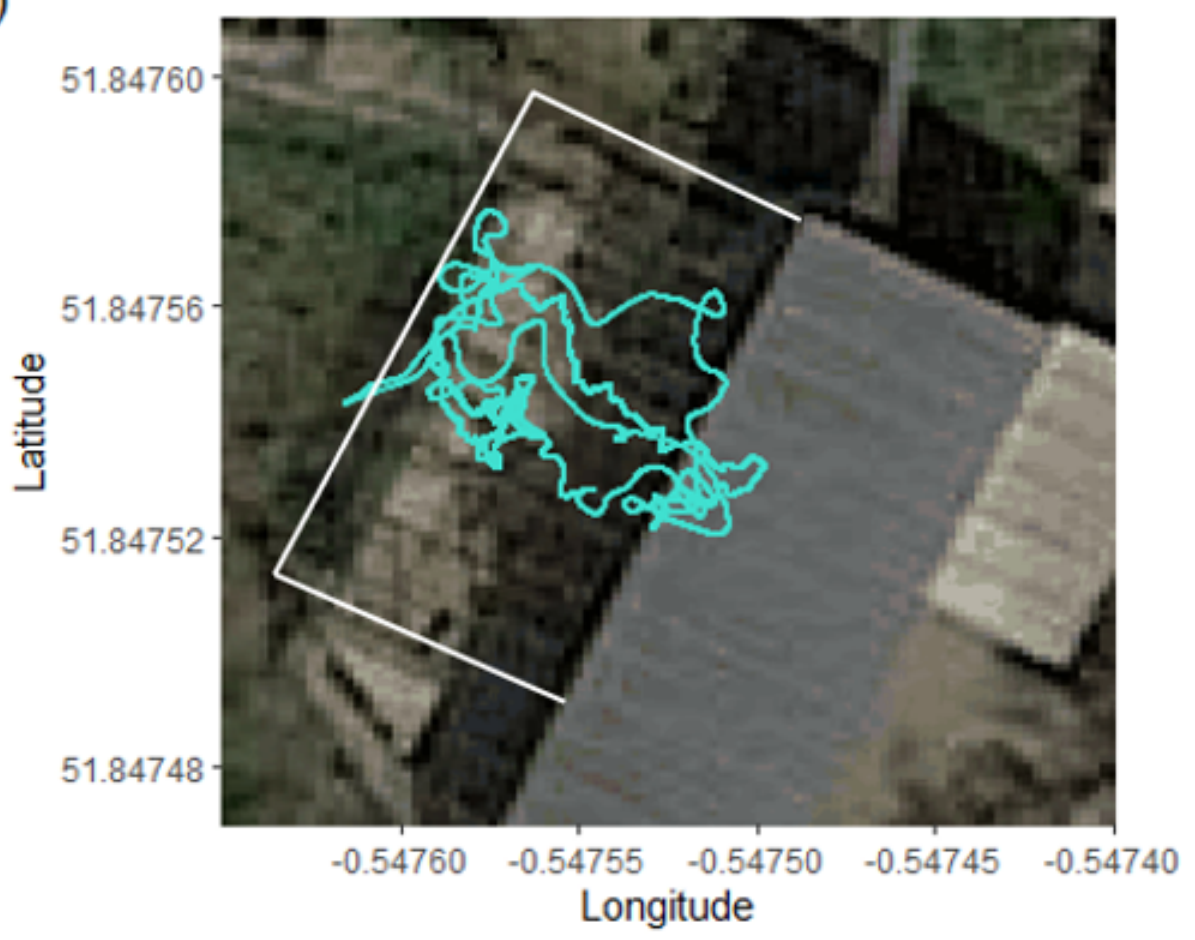

(b)

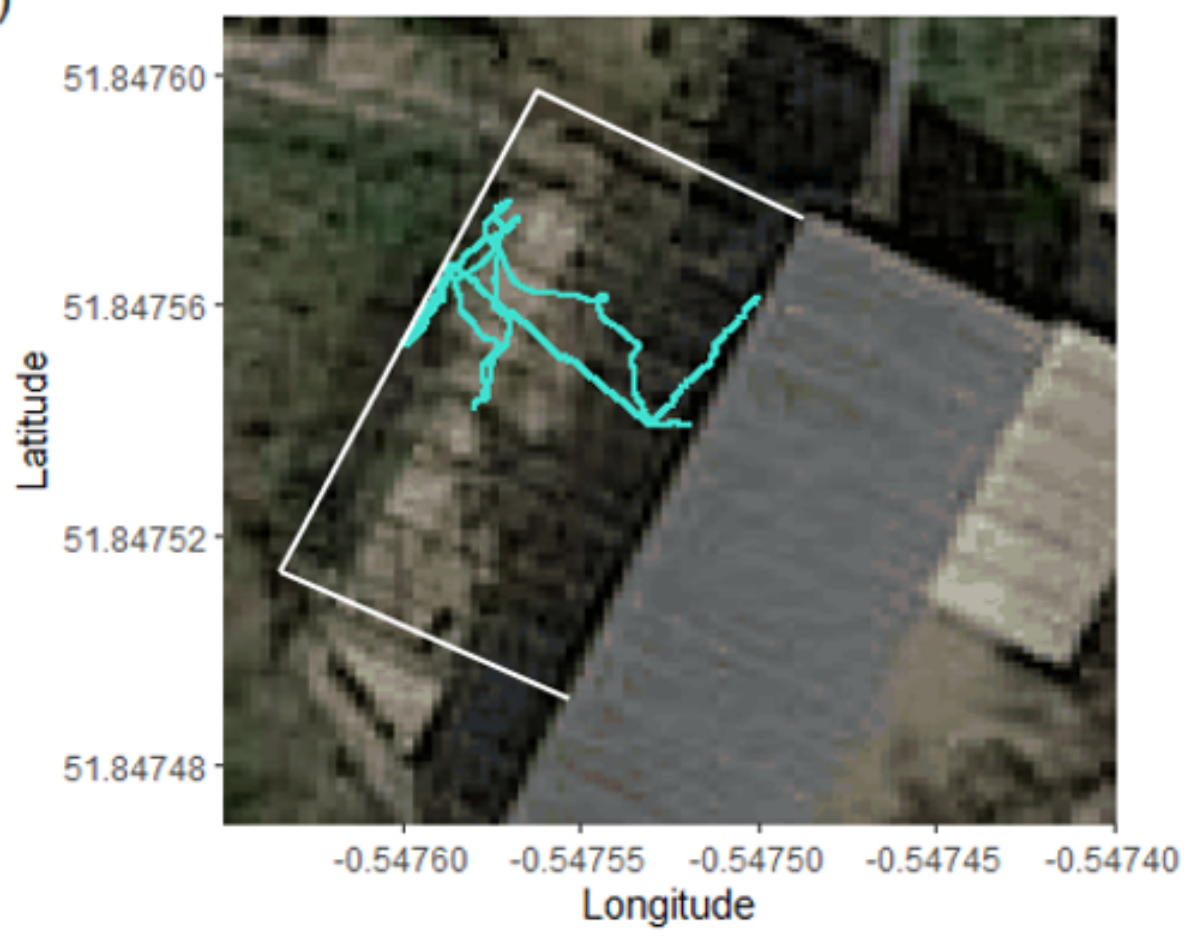

Figure 6

Moving in and out of the house to the small outdoor area on the night the wild dogs arrived in Whipsnade (a) Brandy, (b) BeeBee. The tracks relate to the same two-hour period with 6 and 14 longitude and latitude coordinates for correction respectively, taken opportunistically based on confirmed individual presence at 
a landmark location. The white lines outline the outdoor portion of the enclosure which was accessible to the wild dogs on the day of arrival.

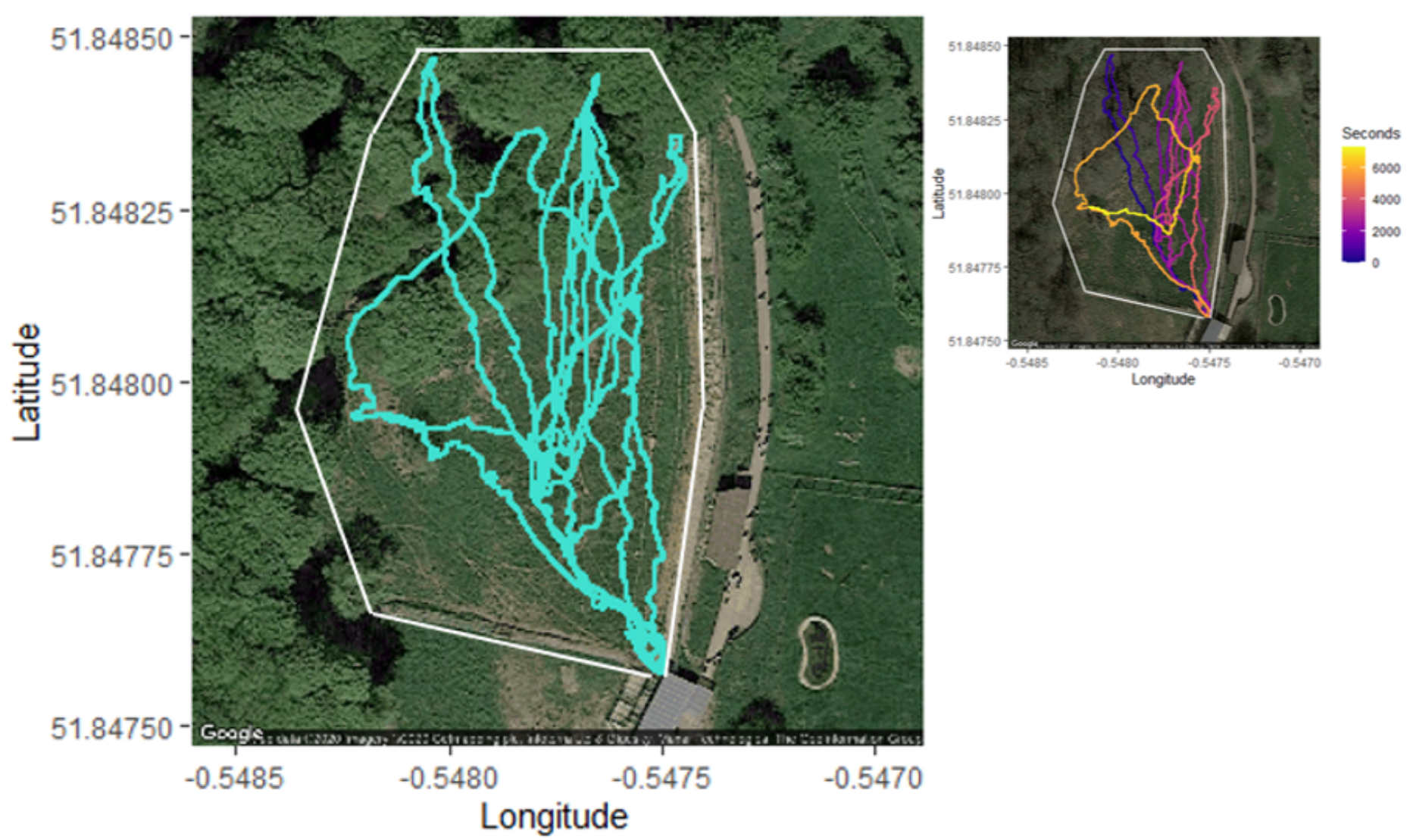

\section{Figure 7}

A $1 \mathrm{~Hz}$ dead-reckoned track obtained from $20 \mathrm{~Hz}$ Daily Diary data representing the first exploration of a new outdoor enclosure in a female African wild dog yearling. 27 longitude and latitude coordinates were used in path correction over the two-hour period. The inset represents the same track coloured by time, moving from darker (blue) to lighter (yellow) colours. 
(a)

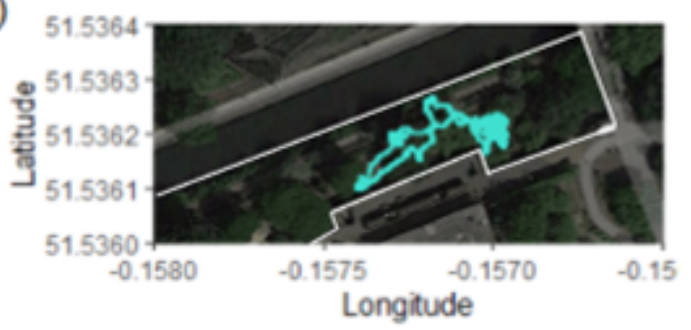

(c)

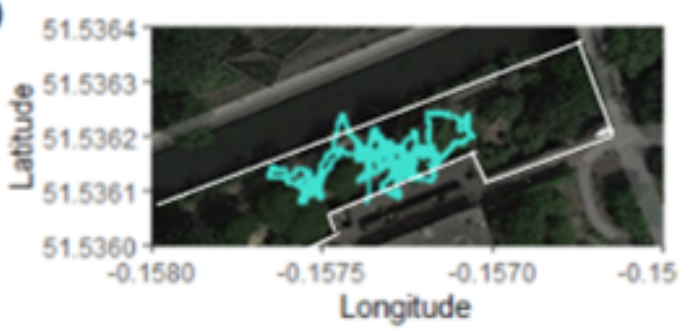

(e)

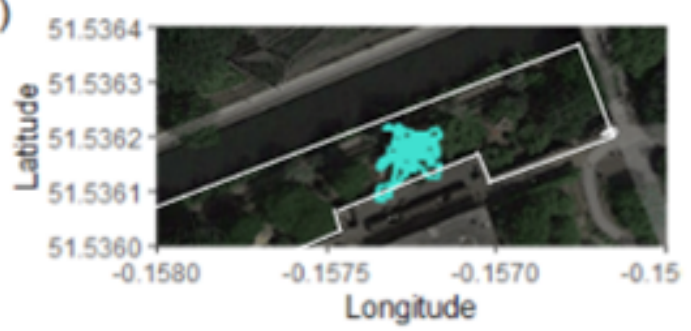

(b)

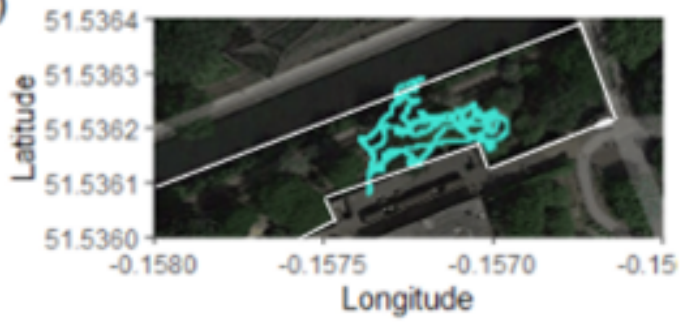

(d)

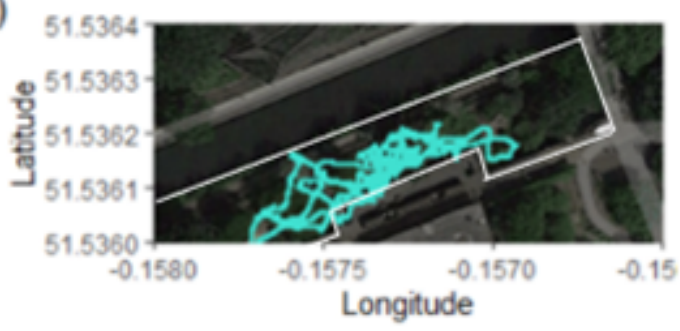

(f)

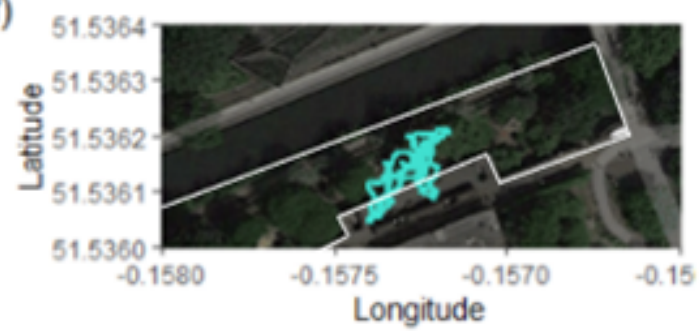

\section{Figure 8}

Three 12-hour dead-reckoned tracks for each of the two male African wild dogs which were collared in London Zoo, corresponding with different food days. The left column shows data from Selous (20 Hz) and the right column shows data from Kruger $(40 \mathrm{~Hz})$. The upper row shows tracks from a day where a partial pony carcass was fed, the middle row shows tracks when rabbits were fed and the lower row shows tracks from a day where meat pieces were fed via tongs. All dead-reckoned tracks were produced at $1 \mathrm{~Hz}$. The white lines indicate outdoor enclosure boundaries, though access to underground indoor housing was available to the south as shown in Figure 2. 

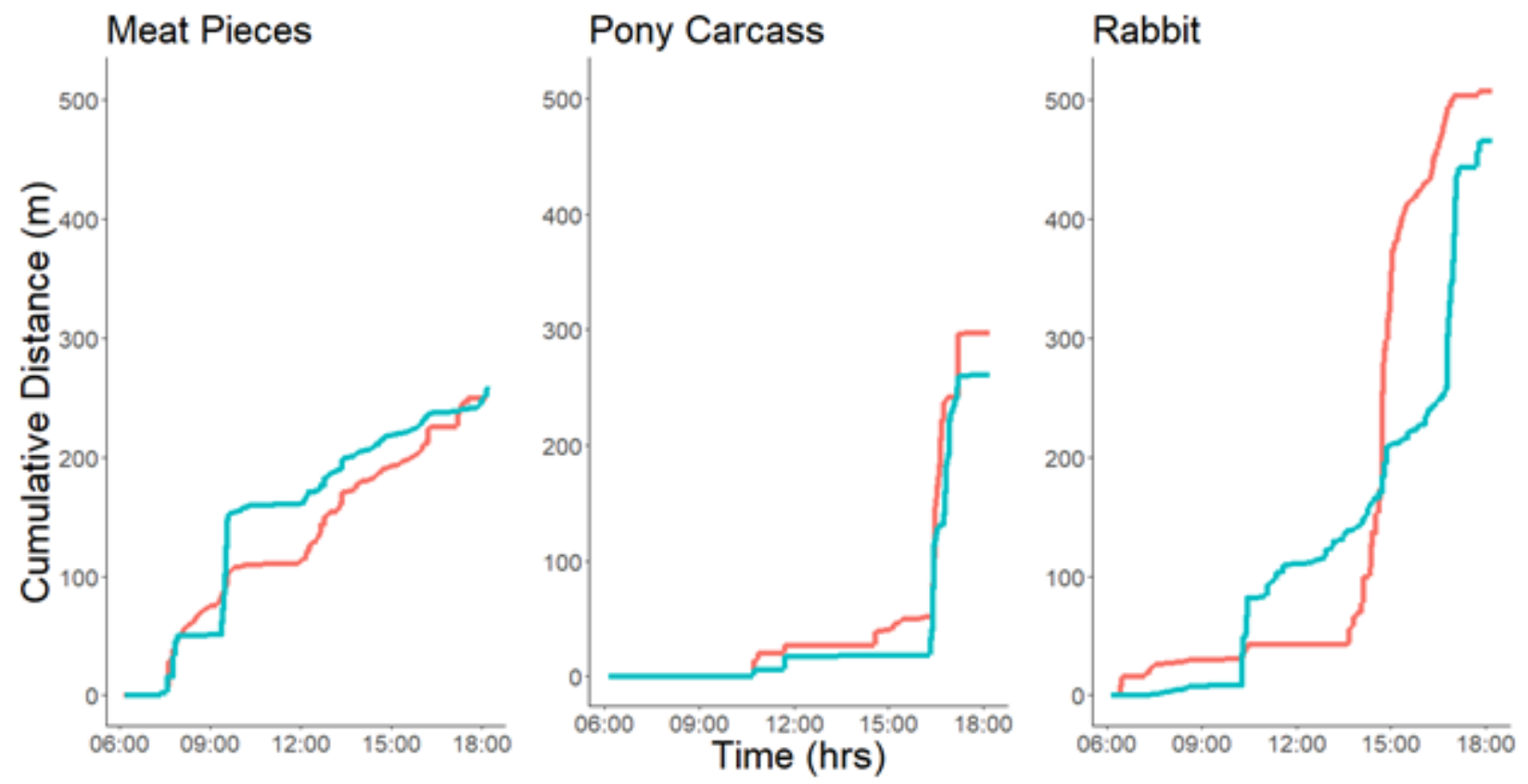

Figure 9

Cumulative distance moved per individual derived from the dead-reckoned data for three days with three different feeding schedules. The meat pieces and pony carcass feed days shown depict similar distances moved, while the rabbit feed day shows larger distance covered. (Kruger data shown in salmon, Selous data shown in blue). 